\title{
Evaluación fisicoquímica y sensorial de un pan tipo baguette utilizando harinas de trigo (Triticum spp) y chícharo (Pisum sativum L.)
}

\author{
Physicochemical and sensory evaluation of a baguette bread using wheat (Triticum spp) \\ and pea (Pisum sativum L.) flours
}

\begin{abstract}
María de la Concepción Calvo-Carrillo', Oliverio Xicoténcatl López-Méndez², María Elena Carranco-Jáuregui*, Jared Marines ${ }^{2}$

Departamento de Nutrición Animal Dr. Fernando Pérez-Gil Romo. Instituto Nacional de Ciencias Médicas y Nutrición Salvador Zubirán. Vasco de Quiroga No. 15, Colonia Belisario Domínguez Sección XVI, Alcaldía Tlalpan, C.P. 14080, Ciudad de México, México.

2 The Culinary Central, Felix Parra No. 92, Col. San José Insurgentes, Alcaldía Benito Juárez, C.P. 03900, Ciudad de México, México.
\end{abstract}

\section{RESUMEN}

El objetivo de esta investigación fue elaborar un pan salado tipo baguette con la técnica de masa esponja incorporando a la harina de trigo (HT) 10, 15 y $20 \%$ de harina de chícharo (HCh) y evaluar su efecto en tiempo de amasado y fermentación en las masas a través del análisis físico de los panes (pérdida de humedad, peso del pan, volumen específico, color), composición química (humedad, proteína cruda, extracto etéreo, cenizas, fibra cruda, carbohidratos totales y perfil de aminoácidos) y evaluación sensorial (color, olor, textura, sabor y aspecto general). Se llevó a cabo análisis de varianza (ANDEVA). El mejor tiempo de amasado fue para la masa con $20 \%$ y de fermentación al $10 \%$ con $\mathrm{HCh}$, volumen específico mayor para $\mathrm{HCh} 15 \%$ y para color (variables L, a* $y$ $\left.b^{*}\right)$ no hubo diferencia estadística $(p>0.05)$. Tanto la proteína como perfil de aminoácidos se fueron incrementando al aumentar la inclusión de HCh. Evaluación sensorial, color, olor, textura, sabor y aspecto general, con respecto al testigo, el pan que obtuvo la mejor calificación (gusta) fue al $15 \%$ de $\mathrm{HCh}$. En general, el pan que presentó los mejores atributos fue al $15 \%$ con $\mathrm{HCh}$.

Palabras clave: Pan baguette, harina de trigo, harina de chícharo, masa esponja, propiedades fisicoquímicas.

\section{ABSTRACT}

The aim of this work was to prepare a salty bread with the sponge dough technique incorporating 10, 15 and $20 \%$ pea meal $(\mathrm{HCh})$ to wheat meal $(\mathrm{HT})$, and evaluate its effect in kneading and fermentation time in the doughs and analytical tests on breads (loss of moisture, bread weight, specific volume, color), chemical composition (moisture, crude protein, ether extract, ash, crude fiber, total carbohydrates and amino acid profile) and sensory evaluation (color, smell, texture, taste and general appearance). An analysis of variance (ANOVA) was carried out for all variables. The best kneading time was for the dough with $20 \%$ and fermentation at $10 \%$ with $\mathrm{HCh}$, higher specific volume for $\mathrm{HCh} 15 \%$, and for color (variables $L, a{ }^{*}$ and $b{ }^{*}$ ) there was no statistical difference ( $p>0.05$ ). Both protein and amino acid profile increased as did the inclusion of $\mathrm{HCh}$. The sensory evaluation, color, smell, texture, flavor and general appearance with respect to the control, the bread with $15 \% \mathrm{HCh}$ obtained the best rating (like). The bread with $15 \% \mathrm{HCh}$ was the one that presented the best attributes.

Keywords: Baguette bread, wheat flour, pea flour, sponge dough, physicochemical properties.

\section{INTRODUCCIÓN}

El pan, en latín pannus que significa masa blanca, es un alimento tradicional que se consume en todo el mundo y se prepara principalmente de harina y agua, a veces lleva levadura y sal (Espino et al., 2016). Uno de los cereales más utilizados para la elaboración de la masa para pan es el trigo, pero también se pueden elaborar de cebada, maíz, centeno y arroz y así mismo se pueden agregar a la masa manteca de cerdo, mantequilla, aceites vegetales, huevos, azúcar, especias, frutos secos y semillas, todo lo anterior con el propósito de mejorar su sabor (Hensperger et al., 2002).

México se encuentra entre los países con una mayor variedad de pan en el mundo (cerca de 2,000 variedades dulces y 300 saladas). Actualmente el consumo de éste es de $33.5 \mathrm{~kg}$ anuales per cápita, de los cuales entre $70-75 \%$ es pan blanco y entre $25-30 \%$ es pan dulce, galletas y pasteles (ANPROPAN, 2018; CANAINPA, 2018).

La harina de trigo es el principal ingrediente en la elaboración de pan por tener las proteínas gluteninas y gliadinas que, al mezclarse con agua, forman el gluten que al combinarse con el almidón forman estructuras que favorecen la retención de gases para, después de la cocción, tener un producto elástico y poroso. Aproximadamente el $85 \%$ del total de las proteínas están representadas por estas dos en una proporción de 3:2 (glutenina:gliadina). Cada una de ellas tiene un efecto sobre las características del gluten. En éste las gluteninas se encuentran polimerizadas mediante puentes disulfuro formando un esqueleto insoluble. Su firmeza depende del tipo de subunidades implicadas y el grado de polimerización, por lo que la presencia de aminoácidos que favorezcan los puentes disulfuro es de importancia. La cisteína es el aminoácido con mayor actividad en la formación de puentes disulfuro intra e intermolecularmente y son las res-

*Autor para correspondencia: María Elena Carranco-Jáuregui Correo electrónico: rexprimero@hotmail.com

Recibido: 20 de febrero de 2020 Aceptado: 18 de junio de 2020 
ponsables de la elasticidad de la masa, pero no intervienen en la cohesividad (Belitz y Grosch, 1992).

Por otro lado, las gliadinas son polímeros heterogéneos con puentes disulfuro intramoleculares que, al hidratarse proporcionan una viscosidad extensible, cohesiva pero no elástica. En el gluten las gliadinas quedan atrapadas en el esqueleto de las gluteninas, dándole tersura y maleabilidad a la masa. Un exceso de gliadinas, en relación con las gluteninas, tiene como consecuencia que el gluten se vuelva débil, permeable y no retenga el dióxido de carbono, por lo tanto, la masa colapsa (Badui, 2006).

En general todos los aminoácidos que participan en la formación del gluten tienen un efecto en la funcionalidad del gluten. Se ha reportado que hay un $6 \%$ de aminoácidos ionizables, $45 \%$ de polares y $49 \%$ de apolares, además de un alto contenido de prolina y glutamina 14 y $37 \%$ del total de aminoácidos. El objetivo es favorecer la formación de puentes de hidrógeno inter e intramoleculares, mientras que los aminoácidos azufrados, además, participan en la formación de los puentes disulfuro inter e intramoleculares. Todo esto se logra a través del amasado y de la integración del resto de los componentes químicos de los insumos utilizados. (Badui, 2006).

Sin embargo, el trigo es deficiente en el aminoácido esencial lisina y bajo en fibra. Por tal motivo, se debe incursionar en el estudio de harinas no convencionales como las de leguminosas que son buena fuente de lisina y triptófano pero deficientes en metionina (Torres et al., 2014). Estas harinas podrían ser de chícharo, garbanzo, lenteja, frijol, etc. que se obtienen directamente de la molienda de las semillas que, previamente fueron escaldadas, remojadas y cocidas para eliminar los factores antinutricios presentes en ellas, seguidas de un secado y molido. El incorporar estas harinas en la elaboración de panes ayuda a tener un producto alimenticio considerado como funcional, ya que puede proporcionar efectos benéficos para la salud, por lo que, la utilización de nuevas fuentes de ingredientes se ha considerado una alternativa para mejorar la dieta (Oliete y Gómez, 2006; Zuleta et al., 2012).

En general, el contenido de proteína de la harina de trigo empleada para la elaboración del pan va de 8.5 a $13 \%$, mientras que una harina de leguminosas como la de chícharo es de $21 \%$ y la de soya $30 \%$ en promedio. Actualmente la industria panadera en el país (artesanal e industrial), busca mejorar las cualidades sensoriales y propiedades nutritivas del pan mediante la formulación de nuevos productos que aporten beneficios a la salud del consumidor (aumento del valor biológico de la proteína, mayor aporte de fibra, reducción de grasa y azúcar, etc.), así como la incorporación de ingredientes que incrementen el rendimiento del producto, su vida de anaquel y/o modifiquen alguna cualidad sensorial en el mismo (suavidad, textura, color, sabor y aroma). Si la combinación de cereales y leguminosas permite tener una proteína de mayor valor biológico por la combinación de sus aminoácidos, se deben buscar opciones para que se pueda ingerir de forma más económica y variada productos que ayuden a consumir más proteína y de mejor calidad. La complementación proteica ha funcionado satisfactoriamente en los individuos o colectivos de los países pobres donde hay deficiencia en el consumo de proteínas y dificultades para cubrir las necesidades energéticas o simplemente cuando se presenta el primer caso (Alasino et al., 2008; Mohammed et al., 2012).

Por lo tanto, se busca utilizar otras harinas que se puedan combinar con la de trigo y una alternativa disponible es la harina de chícharo que, como un ingrediente más en la elaboración de pan puede mejorar las cualidades sensoriales del producto terminado e incrementar el valor de la proteína y del aminoácido lisina. Otra ventaja que se puede lograr al utilizar esta harina es que se genera una mayor estabilidad y volumen de miga provocando un retraso en el envejecimiento del pan (Alasino et al., 2008). Por lo que el objetivo de esta investigación fue determinar el efecto de la incorporación de harina de chícharo a la harina de trigo en el tiempo de amasado y fermentación durante la elaboración de un pan salado tipo baguette sobre sus características fisicoquímicas y sensoriales.

\section{MATERIALES Y MÉTODOS}

Se seleccionó un pan tipo baguette (del francés "varita"), variedad que se caracteriza por ser más largo que ancho y de corteza crujiente. Se elaboró en los laboratorios de panificación de la escuela Gastronómica The Culinary Central, Ciudad de México, México.

Se utilizó harina refinada de trigo (HT) de fuerza con un contenido de proteína del $13.5 \%$ (Espiga ${ }^{\oplus}$ ), harina de chícharo (HCh) (USA Dry Pea Lentil Counci $\left.{ }^{\oplus}\right)$, agua purificada, levadura fresca (Azteca ${ }^{\circledast}$ ), sal cristalina (El Cisne ${ }^{\circledast}$ ) y azúcar blanca (Dominó ${ }^{\oplus}$.

Fermentador industrial eléctrico (Pan CRT, FoxSteel, México), horno de convección (Turbolino, Grupo Alpha Simet, S.A. de C.V., México), batidora con aspa tipo gancho para amasado (Kitchen Aid, México), báscula capacidad 5 kg/g (Metaltex, México S.A de C.V.), balanza analítica capacidad $500 \mathrm{~g}$ con una sensibilidad de $10 \mathrm{mg}$ (OHAUS de México S.A. de C.V.), charolas para horno, espiguero, mesa de trabajo, tazones de acero inoxidable y de vidrio, espátulas, cucharas medidoras, cuchillos, pinzas, raspa de plástico, rodillo y rejilla.

\section{Elaboración del pan (masa madre)}

Se hidrataron $2 \mathrm{~g}$ la levadura en diferentes cantidades de agua y se dejaron reposar por $5 \mathrm{~min}$. Se mezclaron los ingredientes secos: para el pan testigo: harina de trigo $(\mathrm{HT})$, azúcar y sal y para las mezclas experimentales se incorporó a la harina de trigo la harina de chícharo $(\mathrm{HCh})$ en 10, 15 y 20 $\%$, se colocaron en el tazón de la batidora, se añadió agua y la levadura hidratada, se mezclaron con gancho hasta la incorporación total de ingredientes. La masa se colocó en un bowl, se cubrió y se dejó fermentar a temperatura ambiente $\left(25^{\circ}\right.$ $\mathrm{C} / 4 \mathrm{~h}$ ) hasta duplicar su tamaño y se reservaron (Tabla 1). 
Tabla 1. Formulaciones de masas madre de acuerdo con los lineamientos en panadería y formulaciones de acuerdo con el porcentaje panadero para pan tipo baguette.

Table 1. Formulations of mother masses according to the guidelines in bakery, and formulations according to baker's percentage for bread baguette type.

\begin{tabular}{|c|c|c|c|c|}
\hline \multicolumn{5}{|c|}{$\begin{array}{l}\text { Formulación de acuerdo con lineamientos en panadería para la elaboración } \\
\qquad \text { de la masa madre (\%) }\end{array}$} \\
\hline \multirow[b]{2}{*}{ Ingredientes } & \multirow[b]{2}{*}{$\begin{array}{l}\text { Formulación } \\
\text { testigo (FT) }\end{array}$} & \multicolumn{3}{|c|}{ Niveles de sustitución } \\
\hline & & $\begin{array}{l}\mathrm{FT}+10 \% \text { harina } \\
\text { de chícharo }\end{array}$ & $\begin{array}{l}\mathrm{FT}+15 \% \text { harina } \\
\text { de chícharo }\end{array}$ & $\begin{array}{l}\mathrm{FT}+20 \% \text { harina } \\
\text { de chícharo }\end{array}$ \\
\hline Harina de trigo & 100 & 90 & 85 & 80 \\
\hline Harina de chícharo & 0 & 10 & 15 & 20 \\
\hline Agua & 66 & 70 & 70 & 73 \\
\hline Levadura & 2 & 2 & 2 & 2 \\
\hline Azúcar & 7 & 7 & 7 & 7 \\
\hline \multicolumn{5}{|c|}{ Formulaciones de acuerdo con el porcentaje panadero para la elaboración de baguette (\%) } \\
\hline Harina de trigo & 100 & 90 & 85 & 80 \\
\hline Harina de chícharo & 0 & 10 & 15 & 20 \\
\hline Agua & 60 & 62 & 62 & 66 \\
\hline Sal & 2 & 2 & 2 & 2 \\
\hline Masa madre & 50 & 0 & 0 & 0 \\
\hline Masa madre $10 \%$ & 0 & 50 & 0 & 0 \\
\hline Masa madre $15 \%$ & 0 & 0 & 50 & 0 \\
\hline Masa madre $20 \%$ & 0 & 0 & 0 & 50 \\
\hline Levadura & 3 & 3 & 3 & 3 \\
\hline Azúcar & 4 & 4 & 4 & 4 \\
\hline
\end{tabular}

FT= Fórmula Testigo

\section{Elaboración del pan con harina de chícharo por el méto- do de masa-esponja}

Para la elaboración de las baguettes se tomó como referencia las cantidades de la baguette testigo y de estas cantidades se procedió a desarrollar 3 formulaciones sustituyendo a la HT por 10, 15 y $20 \%$ de $\mathrm{HCh}$, las cuales se mencionan en la Tabla 1. Se mezclaron los ingredientes secos y se colocaron en el tazón de la batidora, añadiendo el resto del agua y la masa madre. Todo se mezcló con gancho hasta el desarrollo del gluten (punto de liga) (5-8 $\mathrm{min}$ ) y se colocó en un bowl, se dejó fermentar $\left(37^{\circ} \mathrm{C} / 40-60 \mathrm{~min}\right.$ ) hasta duplicar su tamaño. Una vez duplicado su tamaño se desgasificó, se cortó en porciones de $100 \mathrm{~g}$, se les dio forma de baguette, se colocaron en charolas y se fermentaron por segunda vez (37 ${ }^{\circ} \mathrm{C} / 20-40 \mathrm{~min}$ ), ya duplicado su tamaño se realizaron cortes transversales en la superficie del pan, se colocaron en horno precalentado a $225^{\circ} \mathrm{C} / 10 \mathrm{~min}$. Las charolas con los panes (las 4 formulaciones) se metieron al horno al mismo tiempo a $185-220^{\circ} \mathrm{C} /$ con vapor inicial de $15-20 \mathrm{~s}$, y se hornearon por $30 \mathrm{~min}$. Ya cocido el pan se dejó enfriar sobre una rejilla y se guardaron en bolsas de papel para su posterior análisis.

\section{Métodos analíticos \\ Análisis físicos a las masas y pan}

Se evaluó tiempo de amasado durante 10 min con velocidad 4 de la batidora y la fermentación de las masas a partir del reposo hasta duplicar su tamaño y se midió el tiempo con un cronómetro. Además, se les determinó peso (g), \% peso-pan y \% pérdida de humedad. Éste último parámetro se midió por diferencia de peso del pan antes de hornearlo y el peso del pan ya horneado y frío.
El volumen específico se midió por el método de desplazamiento de semillas (colza), adaptación del método 10-05.01 de la AACC (2000). En una probeta graduada de plástico con capacidad de $2000 \mathrm{~mL}$ (diámetro de $9.4 \mathrm{~cm}$ y altura $46 \mathrm{~cm}$ ) se colocaron las semillas hasta los $1200 \mathrm{~mL}$, después se vaciaron y se introdujo el pan baguette en el cilindro, se añadieron las semillas y se midió la distancia del desplazamiento de éstas a partir de los $1200 \mathrm{~mL}$, la diferencia es considerada como el volumen del pan. Los cálculos se llevaron a cabo de acuerdo con la siguiente fórmula: $V=\pi$ $r^{2} D$, donde $V=$ volumen del pan $\left(\mathrm{cm}^{3}\right), r^{2}=$ radio del cilindro (cm) y $\mathrm{D}=$ Distancia desplazada desde la marca $(\mathrm{cm})$. Por otra parte, el volumen específico se determinó: $\mathrm{VE}=\mathrm{v} / \mathrm{m}$, donde: $\mathrm{v}=$ volumen desplazado $\left(\mathrm{cm}^{3}\right)$ y $\mathrm{m}=$ peso del pan $(\mathrm{g})$.

Los parámetros de color L [luminosidad (100) a negro (0)], a* [rojo (+ v) a verde (-v)], b* [amarillo (+ v) a azul (-v)] de los panes horneados fueron evaluados en 4 puntos diferentes de la parte externa del pan (frente, medio lateral, posterior y centro) medidos con un colorímetro Chroma Meter CR-300 (Minolta Co. Osaka, Japan) utilizando el sistema Space color CIE Lab equipado con un sistema observado a $2^{\circ}$ y calibrado con una loseta blanca y un D-65 como fuente iluminante (Mathias-Rettig y Ah-Hen, 2014).

\section{Composición química de los panes}

Se llevaron a cabo de acuerdo a los métodos estandarizados descritos en AOAC (2005): Humedad por estufa de secado (método 934.03), proteína cruda método de Kjeldahl (método 976.05), extracto etéreo método de Soxhlet (método 2003.06), cenizas por calcinación (método 942.05), fibra cruda por hidrólisis ácido-alcalina (método 962.09), carbohi- 
dratos (por diferencia) y contenido de aminoácidos por cromatografía de intercambio iónico y por espectrofotometría ultravioleta-visible (INCMNSZ, Métodos internos, 2011).

\section{Evaluación sensorial}

Los panes se rebanaron y se presentaron en un plato color blanco etiquetado aleatoriamente, se proporcionó un vaso con agua y se entregaron cuestionarios a 33 jueces no entrenados, pero consumidores habituales de pan. Se evaluaron las variables de color, olor, textura, sabor y aspecto general, aplicando una escala hedónica de 5 puntos ( $1=$ disgusta mucho; $2=$ disgusta; $3=$ ni gusta ni disgusta; $4=$ gusta $y$ $5=$ gusta mucho) (Anzaldúa-Morales, 2014).

\section{Análisis estadístico}

Para todas las variables se llevó a cabo un análisis de varianza (ANDEVA) con $95 \%$ de confianza, utilizando el programa estadístico SAS V9.0 (2000).

\section{RESULTADOS Y DISCUSIÓN}

El identificar y mejorar las propiedades tecno-funcionales de harinas de leguminosas es esencial para determinar los posibles usos de éstas como ingredientes alimentarios, así como proporcionar datos de cómo se comportarían en un alimento y su papel durante la preparación, elaboración y almacenamiento de éstos y su correlación con las propiedades sensoriales. Al trabajar la elaboración de panes tanto testigo (HT) como con HCh, se observaron los siguientes cambios: se presentó una reducción en tiempo de amasado conforme se fue aumentando la cantidad de $\mathrm{HCh}$. El pan testigo desarrolló la fuerza del gluten a los 8 min de amasado a velocidad media y los panes con 10, 15 y $20 \%$ de HCh lo desarrollaron a los 7,6 y 5 min respectivamente. Esto se pudiera explicar en función del tipo de proteínas que se encuentran en las harinas: en $\mathrm{HT}$ son glutelinas y prolaminas mientras que en $\mathrm{HCh}$ predominan las globulinas que integran más rápidamente el agua, lo que se vio reflejado en el tiempo de amasado.

La finalidad de tener un buen gluten es que la red viscoelástica logre retener los gases $\left(\mathrm{CO}_{2}\right.$ y etanol) producidos durante la fermentación y el vapor de agua que se libera durante la cocción; esto es lo que da el esponjamiento del pan. Se ha reportado que la suplementación de harina de trigo con harinas con alto contenido de proteínas globulares y albúminas, como en las leguminosas, afecta negativamente las propiedades viscoelásticas de la masa. Se observa una disminución en el volumen de la hogaza al interferir con la formación de la red del gluten. En el caso de las proteínas de las leguminosas se ha reportado que están conformadas, en general, de un $70 \%$ de globulinas, 10 a $20 \%$ de albúmina, 10 a $15 \%$ de glutelinas y el resto de las prolaminas (5-10\%) (Boza, 1991).

Por lo que, la inclusión de $\mathrm{HCh}$, por el tipo de proteínas que tiene, llega a interferir con la formación del gluten. En relación con las proteínas globulares y las albúminas su efecto se observa en las características de la corteza (Badui, 2006).
El tiempo de fermentación inicial para HT fue de 20 min y las masas con $10 \%$ (25 min), $15 \%$ (30 min) y con $20 \%$ (35 min) de HCh. Durante la segunda fermentación y horneado, el volumen final de los panes con HT y $15 \%$ con $\mathrm{HCh}$ fueron similares. Esto se pudo deber a las propiedades que presenta la proteína de la $\mathrm{HCh}$ que son alta solubilidad, capacidad de retención de agua, acción espumante y emulsificante que favorecieron la textura y estabilidad de la miga (Fleming y Sosulski, 1977). Esto podría deberse a un equilibrio entre los aminoácidos ácido glutámico, glutamina, prolina, leucina, lisina y cisteico que participan activamente en la estabilidad del gluten y este efecto se presentó en el pan con $15 \%$ de $\mathrm{HCh}$; no así con $20 \%$ en donde probablemente por el excedente de estos aminoácidos se quedó en la parte interna de la masa modificando las propiedades de hidratación y elasticidad del gluten (Pyle, 1982).

En cuanto a la formación de miga se observó que el tamaño del alvéolo en general fue uniforme. El gluten logró la elasticidad adecuada para retener los gases provenientes de la fermentación, así como del vapor de agua que tuvo una influencia en el proceso de gelatinización del almidón. Esta reacción inicia a una temperatura de $60^{\circ} \mathrm{C}$. Combinados estos elementos, junto con la desnaturalización del gluten permitió que la porosidad y elasticidad de la miga se reflejaran en el volumen específico y peso de los panes (Figuras 1 y 2) (Luna y Bárcenas, 2011; Gil et al., 2013).

En la Tabla 2 se presentan los resultados de las propiedades físicas del pan observándose que las variables estudiadas presentaron diferencias estadísticas $(p<0.05)$ para las formulaciones $\mathrm{HT}$ y de $\mathrm{HCh}$ al 10 y $20 \%$, y sin diferencia significativa para HT y la inclusión de $15 \%$ de $\mathrm{HCh}(p>0.05)$.

Éstas podrían considerarse como resultado de los cambios o interacciones que tienen lugar entre los componentes del alimento, ejemplo: entre proteínas, proteínas y polisacáridos, lípidos, compuestos fenólicos o ácido fítico (Patane et al., 2004).

Los datos observados se podrían atribuir a que la $\mathrm{HCh}$ no desarrolla gluten, polímero altamente extensible cuando está hidratado. Las proteínas del gluten son consideradas las responsables de la formación de la estructura que retiene el dióxido de carbono de la masa de pan producido por la levadura durante la fermentación lo que induce el aumento de tamaño y/o volumen del pan (Dendy y Dobraszczyk, 2004); es por ello que en este estudio a medida que se aumentó la sustitución de la $\mathrm{HCh}$ se redujo el volumen específico solo al $20 \%$.

En cuanto al color (Tabla 2), el pan tipo baguette se caracteriza por tener una corteza marrón brillante y una textura crujiente, por lo que en este estudio los valores de L (luminosidad, brillantez) de la costra del pan medido en diferentes partes no mostraron diferencias ( $p>0.05$ ) entre el pan con HT y los panes con HCh. El valor más alto fue para la inclusión con $20 \%$ en frente (72.20) y lateral medio (72.41) y para HT en posterior (70.10) y centro (83.60) para $10 \%$ de HCh. Le siguen las formulaciones con 10 y $15 \%$ de $\mathrm{HCh}$ oscilando los valores 


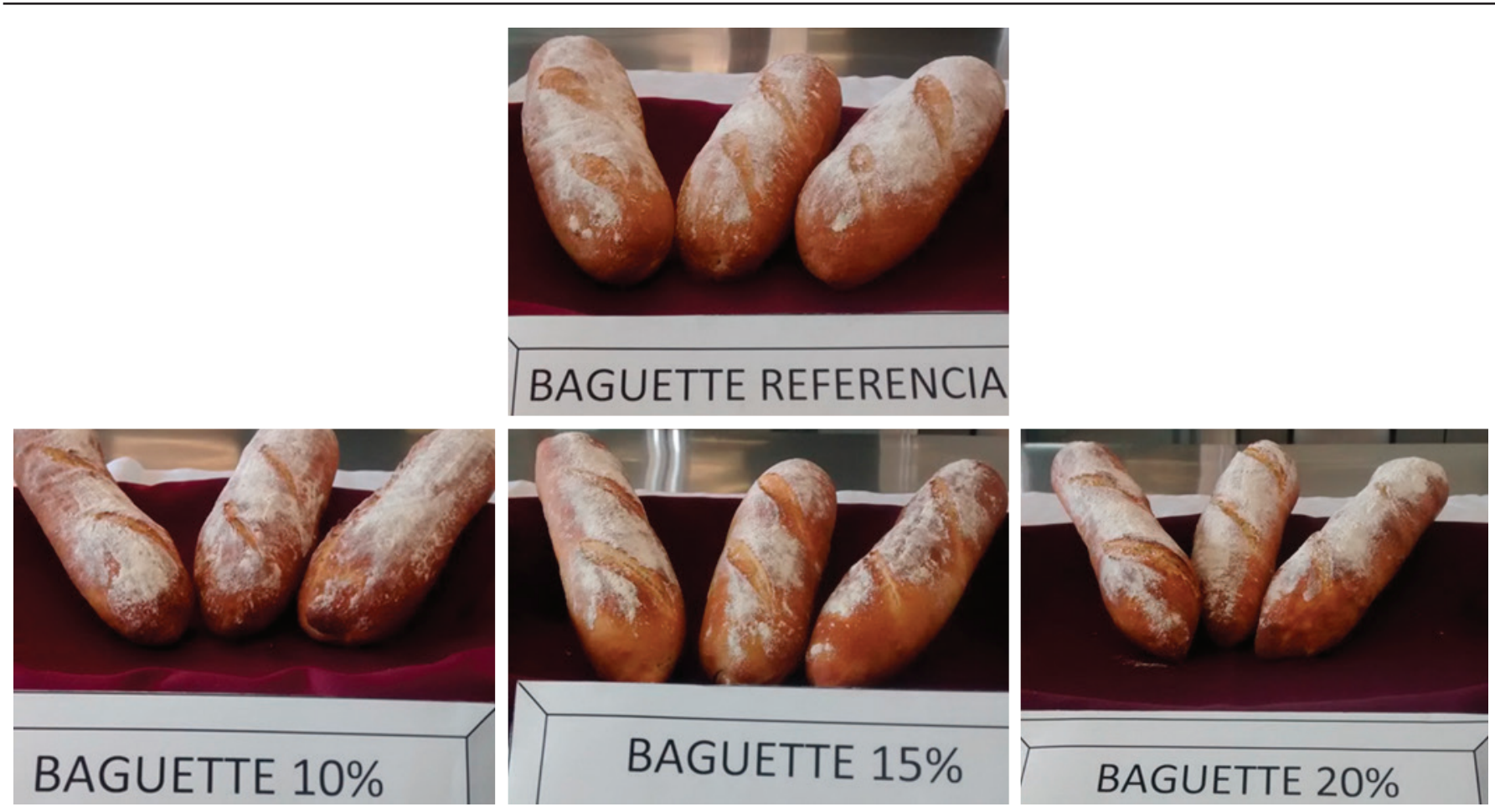

Figura 1. Pan con Harina de trigo (testigo) y con adición de harina de chícharo al 10, 15 y $20 \%$.

Figure 1. Baguettes with wheat flour (control) and with the addition of pea flour at 10, 15 and $20 \%$.

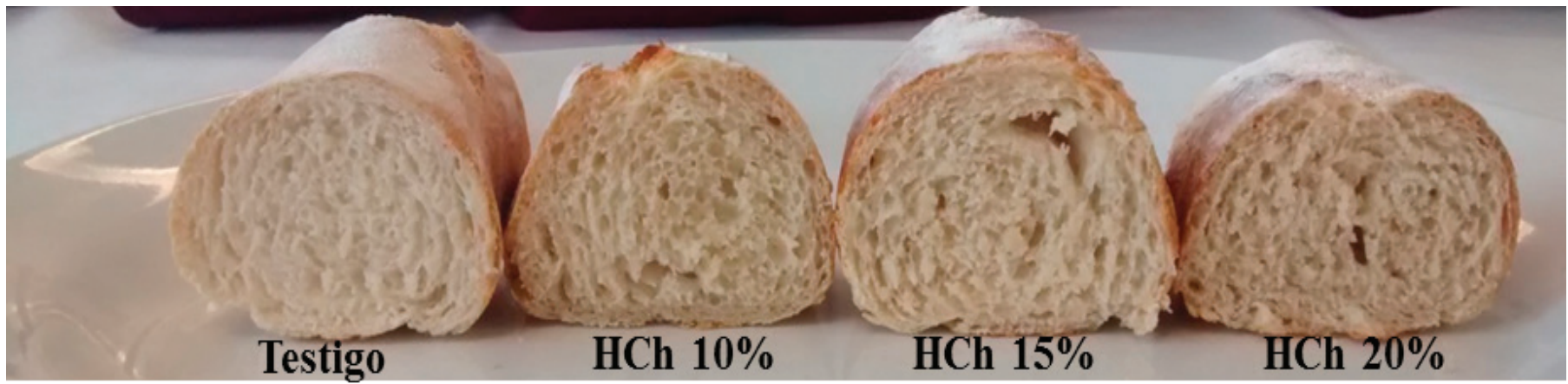

Figura 2. Apariencia visual de la miga del pan con harina de trigo (Testigo) y panes preparados con adición de harina de chícharo 10,15 y $20 \%$. Figure 2. Visual appearance of the bread crumb with wheat flour (Control) and breads prepared with the addition of 10, 15 and $20 \%$ pea flour.

entre 58.38 hasta 82.78 en las variables medidas. En general el valor de $\mathrm{L}$ tuvo una tendencia a aumentar conforme se incrementó el porcentaje de HCh. El valor de L es uno de los parámetros de color más importantes, que puede tener un impacto directo en el valor comercial de un producto (Mohammed et al., 2012).

Para la corteza, el valor de $a^{*}$ fue aumentando conforme se incrementó la inclusión de $\mathrm{HCh}$, lo que indica un tono rojizo de la corteza del pan; sin embargo, se observó diferencia significativa $(p<0.05)$ en la medición del centro de este siendo el valor más alto para las muestras con $15 \%$ y menor para el $10 \%$ con $\mathrm{HCh}$. Pero los resultados en general estuvieron de acuerdo con la observación visual reportada en las pruebas sensoriales.

Los valores de $b^{*}$ de la corteza fueron opuestos a los valores de $a^{*}$ que sugerían que el tono amarillento disminuiría a medida que aumentaba el tono rojizo. No se presentaron diferencias estadísticas ( $p>0.05$ ) entre todos los panes y las 4 mediciones que se hicieron, mostrando que el valor más alto fue para el pan con HCh al $15 \%$ (35.99) y el más bajo para el pan con $\mathrm{HCh}$ al $10 \%$ (22.43).

Los panes de corteza dura se hornean inyectando vapor durante el horneado, lo que ayuda a mantener la corteza suave para que el pan pueda expandirse con rapidez y de manera uniforme, además favorecen la distribución del calor en el horno ayudando al aumento del volumen del pan. Cuando la humedad del vapor reacciona con los almidones de la superficie, algunos de éstos forman dextrinas y luego, al suspender el vapor, éstas caramelizan y doran (color dorado en la superficie del pan) junto con los azúcares en la masa, resultando una corteza delgada, crujiente y brillante (Gisslen, 2001). El color de la corteza se desarrolla durante la etapa de la cocción del pan y está asociado a las reacciones de Maillard y de caramelización, que producen compuestos que afectan, además del color, el sabor (combinación de sensaciones de sabor y aroma) del pan. Por otro lado, las a-amilasas, enzimas 
Tabla 2. Resultados de las propiedades físicas del pan tipo baguette con harina de trigo y con adición de harina de chícharo. Table 2. Results of the physical properties of baguette-type bread with wheat flour and with the addition of pea flour.

\begin{tabular}{|c|c|c|c|c|}
\hline & Baguette testigo & $\begin{array}{l}\text { Baguette con } 10 \% \text { de } \\
\text { harina de chícharo }\end{array}$ & $\begin{array}{l}\text { Baguette con } 15 \% \text { de } \\
\text { harina de chícharo }\end{array}$ & $\begin{array}{c}\text { Baguette con } 20 \% \text { de } \\
\text { harina de chícharo }\end{array}$ \\
\hline $\begin{array}{l}\text { Volumen específico } \\
\text { del pan }\left(\mathrm{cm}^{3} / \mathrm{g}\right)\end{array}$ & $4.50 \mathrm{~b}$ & $4.75 a$ & $4.87 a$ & $3.88 \mathrm{c}$ \\
\hline Peso del pan (g) & $127.80 \mathrm{c}$ & $130.0 \mathrm{~b}$ & $127.80 \mathrm{c}$ & $131.40 a$ \\
\hline $\begin{array}{l}\text { Peso pan pérdida } \\
\text { de humedad (\%) }\end{array}$ & $88.16 \mathrm{c}$ & $89.68 b$ & $88.16 c$ & $90.58 a$ \\
\hline Pérdida de agua (\%) & $11.84 a$ & $10.32 \mathrm{~b}$ & $11.84 a$ & $9.42 \mathrm{c}$ \\
\hline \multicolumn{5}{|c|}{ Color } \\
\hline \multicolumn{5}{|l|}{$\mathrm{L}$} \\
\hline Frente & 68.22 & 58.38 & 58.13 & 72.20 \\
\hline Medio lateral & 69.64 & 59.33 & 61.66 & 72.41 \\
\hline Posterior & 70.10 & 70.46 & 63.61 & 68.77 \\
\hline Centro & 82.78 & 83.60 & 72.35 & 77.64 \\
\hline \multicolumn{5}{|l|}{$a^{*}$} \\
\hline Frente & 9.35 & 12.36 & 13.30 & 7.51 \\
\hline Medio lateral & 8.30 & 13.19 & 12.54 & 6.79 \\
\hline Posterior & 8.91 & 7.91 & 11.41 & 9.10 \\
\hline Centro & $1.29 a b$ & $0.38 b$ & $8.12 \mathrm{a}$ & 4.17ab \\
\hline \multicolumn{5}{|l|}{$b^{*}$} \\
\hline Frente & 32.48 & 32.54 & 35.99 & 30.95 \\
\hline Medio lateral & 30.22 & 33.87 & 35.11 & 30.92 \\
\hline Posterior & 34.85 & 33.52 & 35.38 & 33.93 \\
\hline Centro & 23.19 & 22.43 & 32.06 & 29.75 \\
\hline
\end{tabular}

$\mathrm{n}=5$

El peso de la masa fue igual para todos los panes (145 g).

$a, b, c$ Literales diferentes entre filas son estadísticamente diferentes $(p<0.05)$

Parámetros de color: L=luminosidad (100) a negro (0), $\mathbf{a}^{*}=$ rojo (+ v) a verde $(-\mathrm{v})$ y $\mathbf{b}^{*}=$ amarillo $(+\mathrm{v})$ a azul $(-\mathrm{v})$.

presentes en la harina, hidrolizan el almidón en glucosa y maltosa; parte de éstas son asimiladas por las levaduras produciendo el dióxido de carbono y etanol (fermentación) y otra porción participan en las reacciones de Maillard y caramelización. Por ello, una escasa actividad la a-amilasa de la harina puede dar lugar a cortezas insuficientemente coloreadas (Gisslen, 2001).

Yamsaengsung et al. (2010) estudiaron los efectos de la adición de harina de garbanzo sobre el color de la corteza del pan blanco y de trigo integral, reportando que en el pan blanco la adición de garbanzos aumentó el color amarillo en la miga del pan, mientras que en la corteza las tonalidades fueron más oscuras. Indrani et al. (2007) analizaron la influencia de agregar concentrado de proteína de suero en el color del pan sin levadura y observaron que los panes tenían un alto valor $\left(b^{*}\right)$, lo que representaba un aumento del color amarillo. A medida que el nivel de concentrado de proteína de suero aumentó de $0 \%$ (pan control) al $15 \%$, el color de la costra del pan se volvió opaco y fue más oscura. Kenny et al. (2000) usaron concentrado de proteína de suero en la fabricación de pan como sustituto del trigo y mencionan que los panes tuvieron valores de L (luminosidad) más bajos en comparación con el pan testigo y el color de la corteza fue muy oscuro. La adición de sustitutos de harina de trigo sea cual sea su naturaleza, tiene un efecto en las variables que se utilizan para medir el color, los panes con HT y HCh no tuvieron diferencia significativa con el testigo y la aceptación fue buena.

En la Tabla 3 se presentan los resultados de la composición química reportada en $\mathrm{g} / 100 \mathrm{~g}$ de muestra de los panes con HT y con adición de HCh. Se observa que con $20 \%$ de $\mathrm{HCh}$, los valores de proteína cruda, cenizas, extracto etéreo y fibra cruda fueron mayores que el pan elaborado con HT. No así para las variables de carbohidratos disponibles y energía bruta que fueron mayores para pan testigo (HT). En general, el contenido de proteínas en cereales se encuentra entre el 10 y $12 \%$ y en las leguminosas del 19 al $35 \%$. Por lo que, al aumentar el porcentaje de inclusión de leguminosas la fracción proteínica aumenta, repercutiendo en una disminución en carbohidratos disponibles. Las proteínas de las leguminosas se clasifican en las de reserva o globulinas (70 $\%)$, que constituyen la mayor proporción, funcionales como las albúminas (10-20\%) y estructurales como las glutelinas (10-20\%), sin embargo, por el perfil de aminoácidos, sobre todo en los esenciales, su valor nutrimental es bajo comparado con una proteína de origen animal, pero son una alter- 
Tabla 3. Composición química de pan tipo baguette ( $\mathrm{g} / 100 \mathrm{~g}$ base húmeda/base seca).

Table 3. Chemical composition of bread baguette type ( $\mathrm{g} / 100 \mathrm{~g}$ on a wet basis/dry basis).

\begin{tabular}{lcccc}
\hline & $\begin{array}{c}\text { Baguette testigo } \\
\text { (BT) }\end{array}$ & $\begin{array}{c}\text { BT + 10 \% de Harina } \\
\text { de Chícharo }\end{array}$ & $\begin{array}{c}\text { BT + 15\% de Harina } \\
\text { de Chícharo }\end{array}$ & $\begin{array}{c}\text { BT + 20 \% de Harina } \\
\text { de Chícharo }\end{array}$ \\
\hline Humedad & $37.18 \mathrm{~b}$ & $38.47 \mathrm{ab}$ & $37.69 \mathrm{~b}$ & $40.46 \mathrm{a}$ \\
\hline Proteína cruda & $9.91 / 15.77 \mathrm{c}$ & $10.26 / 16.67 \mathrm{~b}$ & $10.66 / 17.10 \mathrm{~b}$ & $11.49 / 17.62 \mathrm{a}$ \\
\hline Cenizas & $1.59 / 2.54 \mathrm{~b}$ & $1.66 / 2.70 \mathrm{ab}$ & $1.74 / 2.79 \mathrm{a}$ & $1.78 / 2.80 \mathrm{a}$ \\
\hline Extracto etéreo & $0.90 / 1.43 \mathrm{~b}$ & $0.93 / 1.51 \mathrm{~b}$ & $0.97 / 1.55 \mathrm{a}$ & $0.98 / 1.59 \mathrm{a}$ \\
\hline Fibra cruda & $0.48 / 0.77 \mathrm{c}$ & $1.77 / 2.88 \mathrm{~b}$ & $2.45 / 3.94 \mathrm{a}$ & $2.75 / 4.78 \mathrm{a}$ \\
\hline $\begin{array}{l}\text { Carbohidratos } \\
\text { disponibles }\end{array}$ & $49.94 / 79.49 \mathrm{a}$ & $46.92 / 76.25 \mathrm{~b}$ & $46.49 / 74.61 \mathrm{~b}$ & $42.54 / 73.21 \mathrm{c}$ \\
\hline Kcal/100g & $217.77 / 346.65 \mathrm{a}$ & $206.31 / 335.29 \mathrm{~b}$ & $205.35 / 329.56 \mathrm{~b}$ & $190.47 / 319.90 \mathrm{c}$ \\
\hline Kjoules/100g & $911.15 / 1450.41 \mathrm{a}$ & $863.20 / 1402.89 \mathrm{~b}$ & $859.18 / 1378.87 \mathrm{~b}$ & $796.93 / 1338.47 \mathrm{c}$ \\
\hline
\end{tabular}

BT= Baguette Testigo

Se reporta la media de una $\mathrm{n}=3$

${ }^{1} \mathrm{~N} \times 6.25$

$a, b, c$ literales diferentes en cada fila indican diferencias estadísticas $(p<0.05)$

nativa como fuente de nitrógeno para personas que viven en países en desarrollo, que han mostrado que al utilizar la combinación de cereales y leguminosas los aminoácidos se complementan mejorando la calidad de la proteína (Magaña et al., 2011).

Sin embargo, un aspecto importante que se debe tomar en cuenta al utilizar harinas de leguminosas es que contienen compuestos considerados como antinutricios, por ejemplo, la presencia de ácido fítico, inhibidores enzimáticos (factor antitrípsico), hemaglutininas o lectinas, por lo que a través del acondicionamiento de la semilla (cocción, lavado, secado y molido) se puede mejorar el valor nutritivo de esta harina, ya que con los procesos antes mencionados se inactivan estos factores antinutricios (Ros et al., 2010).

En los panes tanto con HT como con la inclusión de HCh la cantidad de extracto etéreo osciló entre 0.90-0.98 \%, debido a que la materia prima fue baja en grasa. Elichalt et al. (2017) estudiaron el contenido de lípidos en pan francés artesanal elaborado solo con HT encontrando una media de $0.28 \%$, ya que en su elaboración no se agrega grasa por lo que este contenido corresponde a los lípidos naturales aportados por la HT, siendo este resultado bajo en comparación a los panes de este estudio, debido a que la $\mathrm{HCh}$ tiene mayor porcentaje de grasa que la $\mathrm{HT}$; sin embargo, este producto sigue teniendo bajos niveles de grasa.

El contenido de carbohidratos disponibles fue mayor en el pan testigo (HT) y menor en la incorporación de HCh al $20 \%$. En la $\mathrm{HCh}$ el carbohidrato predominante es el almidón (75-80 \%) y contiene además oligosacáridos (rafinosa, estaquiosa y verbascosa) que unidos a otros componentes indigestibles propios de la fibra dietaria son los responsables de producir flatulencia en las personas (Ros et al., 2010).

Las leguminosas proporcionan a la dieta una elevada proporción de carbohidratos de digestión lenta, lo que permite utilizarlos en el tratamiento de diversas enfermedades crónicas. Son distintos factores intrínsecos y extrínsecos los que determinan, en la dieta, la velocidad de digestión y absorción de los carbohidratos. Se han considerado como factores intrínsecos al alimento la estructura física o cristalina del almidón, proporción de amilosa/amilopectina, ya que un mayor contenido en amilosa se asocia a una menor digestibilidad (las leguminosas tienen un contenido en amilosa superior al de los cereales), presencia de estructuras que afecten la digestión (p. ej. la testa de las leguminosas), interacción entre el almidón y proteína, la presencia de los componentes de la fibra dietética, inhibidores de los carbohidratasas y de otros antinutrientes (fitatos y lectinas) que llegan a afectar la acción enzimática durante el proceso digestivo. Entre los factores extrínsecos al alimento están el tamaño de partícula, grado de gelatinización del almidón, que está relacionado con la forma de preparación de pan o el proceso tecnológico y el tiempo de tránsito intestinal, todos ellos hacen que los carbohidratos sean más accesibles a las enzimas digestivas $y$, por lo tanto, más digeribles (Ros et al., 2010).

El contenido de aminoácidos presentó diferencias $(p<$ 0.05 ) entre tratamientos con respecto al testigo a excepción del ácido glutámico, glicina y cisteico ( $p>0.05)$, los valores más altos se presentaron para el pan con $20 \%$ de HCh (Tabla 4). Al ser HT deficiente en lisina y no en metionina y $\mathrm{HCh}$ ser deficiente en metionina, pero tener altos niveles de lisina, se deduce que la combinación de estas dos harinas permite una mejor calidad de proteína en los panes (Serna, 2005: Torres et al., 2014). Alasino et al. (2008) observaron que panes elaborados con $\mathrm{HT}$ y $\mathrm{HCh}$, tratada térmicamente, con niveles de inclusión de 5, 10 y $15 \%$ incrementó el valor de la proteína (6 a $16 \%$ ) y lisina (29 hasta $88 \%$ ) para los panes con 5 y $15 \%$ con $\mathrm{HCh}$, además este aminoácido no se vio afectado por el tratamiento térmico; no obstante, se observó una disminución en el volumen específico y las características sensoriales. Estos mismos autores concluyeron que con $5 \%$ de adición de $\mathrm{HCh}$ tratada térmicamente por 1 min se obtuvieron mejores resultados.

En la Tabla 5 se presentan los resultados de la evaluación sensorial de los panes con HT y con adición de HCh. Los datos con respecto al testigo presentaron diferencias $(p<0.05)$ en todas las variables (color, olor, textura, sabor y 
Tabla 4. Contenido de aminoácidos en pan tipo baguette ( $\mathrm{g} / 100 \mathrm{~g}$ de proteína).

Table 4. Amino acid content in bread baguette type ( $\mathrm{g} / 100 \mathrm{~g}$ protein).

\begin{tabular}{|c|c|c|c|c|}
\hline & \multicolumn{4}{|c|}{ Contenido de aminoácidos (g/100 g de proteína) } \\
\hline & $\begin{array}{l}\text { Baguette testigo } \\
\text { (BT) }\end{array}$ & $\begin{array}{c}\text { BT + } 10 \% \text { de Harina } \\
\text { de Chícharo }\end{array}$ & $\begin{array}{c}\text { BT + } 15 \% \text { de Harina } \\
\text { de Chícharo }\end{array}$ & $\begin{array}{c}\text { BT }+20 \% \text { de Harina } \\
\text { de Chícharo }\end{array}$ \\
\hline \multicolumn{5}{|l|}{ Indispensables } \\
\hline Valina & $1.80 c$ & $2.91 \mathrm{ab}$ & $2.56 b$ & $3.43 a$ \\
\hline Isoleusina & $0.87 c$ & $2.79 b$ & $2.52 b$ & $3.32 \mathrm{a}$ \\
\hline Treonina & $1.51 \mathrm{~b}$ & $2.41 \mathrm{a}$ & $2.43 a$ & $2.65 a$ \\
\hline Fenilalanina & $3.23 b$ & $5.00 \mathrm{a}$ & $5.18 \mathrm{a}$ & $5.13 a$ \\
\hline Leucina & $4.79 b$ & $7.93 a$ & $7.88 \mathrm{a}$ & $7.97 a$ \\
\hline Lisina & $2.27 c$ & $4.19 \mathrm{~b}$ & $4.70 \mathrm{ab}$ & $4.83 a$ \\
\hline Metionina & $1.67 \mathrm{~b}$ & $1.86 \mathrm{~b}$ & 1.99ab & $2.24 a$ \\
\hline \multicolumn{5}{|l|}{ Dispensables } \\
\hline Histidina & $2.15 a$ & $1.97 b$ & $2.09 a$ & $2.06 a b$ \\
\hline Ácido aspártico & $4.92 b$ & $5.46 \mathrm{ab}$ & $6.37 a$ & $6.04 a$ \\
\hline Serina & $4.71 b$ & $6.31 a$ & $5.99 a$ & $5.96 a$ \\
\hline Ácido glutámico & $23.44 a$ & $28.45 a$ & $27.26 a$ & $25.78 a$ \\
\hline Prolina & $20.36 a$ & $18.23 b$ & $17.18 \mathrm{c}$ & $13.61 d$ \\
\hline Glicina & $3.27 a$ & $3.50 \mathrm{a}$ & $3.56 a$ & $3.66 a$ \\
\hline Alanina & $2.89 b$ & $3.83 a$ & $4.08 a$ & $3.87 a$ \\
\hline Cisteico & $1.87 a$ & $1.91 \mathrm{a}$ & $1.82 \mathrm{a}$ & $2.01 a$ \\
\hline Tirosina & $1.35 b$ & $2.74 a$ & $2.73 a$ & $2.68 a$ \\
\hline Arginina & $2.21 \mathrm{c}$ & $4.57 \mathrm{~b}$ & $5.24 a b$ & $5.93 a$ \\
\hline
\end{tabular}

Se reporta la media de una $\mathrm{n}=3$

$a, b, c, d$ literales diferentes en cada fila indican diferencias estadísticas $(p<0.05)$

Tabla 5. Resultados de la evaluación sensorial del pan tipo baguette con harina de trigo y con adición de harina de chícharo.

Table 5. Results of the sensory evaluation of bread baguette type with wheat flour and with the addition of pea flour.

\begin{tabular}{lcccc}
\hline & Baguette testigo & $\begin{array}{c}\text { Baguette con 10\% de } \\
\text { harina de chícharo }\end{array}$ & $\begin{array}{c}\text { Baguette con 15\% de } \\
\text { harina de chícharo }\end{array}$ & $\begin{array}{c}\text { Baguette con 20 \% de } \\
\text { harina de chícharo }\end{array}$ \\
\hline Color & $4.51 \mathrm{a}$ & $3.84 \mathrm{~b}$ & $4.57 \mathrm{a}$ & $3.54 \mathrm{c}$ \\
\hline Olor & $4.57 \mathrm{a}$ & $3.72 \mathrm{~b}$ & $4.69 \mathrm{a}$ & $3.57 \mathrm{~b}$ \\
\hline Textura & $4.87 \mathrm{a}$ & $3.87 \mathrm{~b}$ & $4.93 \mathrm{a}$ & $3.30 \mathrm{c}$ \\
\hline Sabor & $4.90 \mathrm{a}$ & $3.54 \mathrm{~b}$ & $4.90 \mathrm{a}$ & $3.54 \mathrm{~b}$ \\
\hline Aspecto general & $4.84 \mathrm{a}$ & $3.78 \mathrm{~b}$ & $4.87 \mathrm{a}$ & $3.12 \mathrm{c}$ \\
\hline
\end{tabular}

Diferentes literales en cada fila son estadísticamente diferentes $(p<0.05)$.

$\mathrm{n}=33$

Escalas: 1= Disgusta mucho; $2=$ Disgusta; $3=$ Indiferente; $4=$ Gusta; $5=$ Gusta mucho

aspecto general) para las inclusiones de 10 y $20 \%$ de $\mathrm{HCh}$ en la escala 3 (ni gusta ni disgusta), mientras que entre el pan testigo y el pan con $15 \%$ de $\mathrm{HCh}$ no mostraron diferencia ( $p$ $>0.05$ ) y fueron los mejor calificados en escala 4 (Gusta), por lo que se puede considerar que los niveles de inclusión al 15 $\%$ de $\mathrm{HCh}$ para la elaboración del pan tipo baguette fue la adecuada.

\section{CONCLUSIONES}

La inclusión de $\mathrm{HCh}$ permitió obtener panes con un mayor contenido de proteína y en cuanto a los aminoácidos se incrementaron a pesar de que algunos de ellos tienen una participación en la generación de las características sensoriales de las muestras. El pan elaborado con $20 \%$ de $\mathrm{HCh}$ presentó un aumento en proteína y aminoácidos con respecto al testigo, sin embargo, el volumen del pan y sus características sensoriales no fueron iguales al testigo, de acuerdo con los resultados del análisis sensorial los jueces no detectaron diferencia entre el pan testigo y el elaborado con inclusión de $15 \%$ de $\mathrm{HCh}$, calificando a estos panes en la escala hedónica de 4 puntos "Gusta" en color, olor, textura, sabor y aspecto general. Finalmente, y de acuerdo con el análisis e interpretación de los resultados obtenidos en este trabajo, se concluye que se pueden combinar HT (harina de 
trigo) con HCh (harina de chícharo) (15\%) para la elaboración de pan tipo baguette.

\section{REFERENCIAS}

AACC. 2000. American Association of Cereal Chemists. Approved Methods of Analysis. 11ed. Method 10-05.01. Guideliness for Measurement of Volumen by Rapeseed Displacement. 2000. AACC International, St. Paul, MN, USA.

AOAC. 2005. Official Methods of Analysis. 18th ed. Association of Official Analytical Chemists. Washington DC, USA.

ANPROPAN. Asociación Nacional de Proveedores Profesionales de la Industria del Pan, Repostería y Similares, A.C. [Consultado 5 Agosto 2019] 2018. Disponible en www. anpropan.org.mx.

Alasino, M.C., Andrich, O.D., Sabbag, N.G., Costa, S.C., de la Torre, M.A. y Sánchez, H.D. 2008. Panificación con harina de arvejas (Pisum sativum) previamente sometidas a inactivación enzimática. Archivos Latinoamericanos de Nutrición. 58 (4): 397-402.

Anzaldúa-Morales, A. 2014. La evaluación sensorial de los alimentos en la teoría y la práctica, pp.70-73, 99-102. Acribia. Zaragoza, España.

Badui, D.S. 2006. Química de los alimentos. 4a ed. Editorial México, Pearson. pp. 224-226.

Belitz, H.D. y Grosch, W. 1992. Química de los alimentos. 2a. ed. Acribia, España. p. 735.

Boza, L. J. 1991. Valor nutritivo de las leguminosas de grano en la alimentación humana y animal. RACVAO (ed.), pp. 71-96. Academia de Ciencias Veterinarias de Andalucía Oriental (Online). http://hdl.handle.net/10396/3797.

CANAINPA. Cámara Nacional de la Industria Panificadora. [Consultado 5 Agosto 2019] 2018. Disponible en: www. canainpa.com.mx.

Dendy, D.A.V, y Dobraszczyk, D.B.J. 2004. Pan: un alimento único. En: Cereales y Productos derivados. Química y Tecnología. D.A.V. Dendy, y D.B.J. Dovoraszczyk (eds.), pp 223-278. Acribia, Zaragoza, España.

Elichalt, M., Russo, M., Vázquez, D., Suburú, G., Tihista, H. y Godiño, M. 2017. Lípidos, sodio y fibra dietética en harina de trigo y pan artesanal en Uruguay: aporte nutricional según recomendaciones para distintos grupos de población. Revista Chilena de Nutrición. 44 (1): 71-78.

Espino, M.S.O., Alfaro, R.R.H. y Güemes, V.N. 2016. Evaluación de los atributos de textura: suavidad y esponjosidad de un pan tipo pambazo con distintas formulaciones. Investigación y Desarrollo en Ciencia y Tecnología de Alimentos. 1 (1): 606611.

Luna-Fernández, M. y Bárcenas-Pozo, M. E. 2011. Envejecimiento del pan: causas y soluciones. Temas Selectos de Ingeniería de Alimentos. 5-2: 40-53.

Fleming, S. y Sosulski, S. 1977. Breadmaking propierties of four concéntrate plants proteins. Cereal Chemistry. 54 (5): 11201140.

Gil, H.A., Juárez, I.M. y Fontecha, A.J. 2013. Influencia de los procesos tecnológicos sobre el valor nutritivo de los alimentos. En: Tratado de Nutrición, Composición y calidad nutritiva de los alimentos. Gil, H.A. ed. Ed. Médica Panamericana. pp 554.

Gisslen, W. 2001. Panadería y Repostería para profesionales. Ed. Limusa Wiley, S.A. de C.V. pp 33-38.
Hensperger, B., Williams, Ch. y Barnhurst, N. 2002. Bread (en inglés). $1^{\mathrm{a}}$ ed. Williams-Sonoma Collection.

Indrani, D., Prabhasankar, P., Rajiv, J. y Rao, G.V. 2007. Influence of whey protein concentrate on the rheological characteristics of dough, microstructure and quality of unleavened flat bread (parotta). Food Research International. 40 (10): 12541260.

INCMNSZ. 2011. Determinación de perfil de aminoácidos por Métodos internos MME-AA-01, MME-AA-02 y MME-AA-03. No. de Acreditación: A-0099-007/11. Dirección de Nutrición, Departamento de Ciencia y Tecnología de los Alimentos. Ciudad de México, México.

Kenny, S., Wehrle, K., Stanton, C.y Arendt, E.K. 2000. Incorporation of dairy ingredients into wheat bread: effects on dough rheology and bread quality. European Food Research and Technology. 210 (6): 391-396.

Magaña, E., Ramírez, B., Torres, P., Sánchez, D. y López, J. 2011. Efecto del contenido de proteína, grasa y levadura en las propiedades viscoelásticas de la masa y la calidad de pan tipo francés. Interciencia. 36 (4): 248-255.

Mathias-Rettig, K. y Ah-Hen, K. 2014. El color en los alimentos un criterio de calidad medible. Agro Sur. 42 (2): 39-48.

Mohammed, A., Maxime, S.G. y Joyce, I.B. 2012. Pea, Lentil and Chickpea Protein Application in Bread Making. Journal of Food Research. 1 (4): 160-173.

Oliete, B. y Gómez, P.M. 2006. Leguminosas. En: De tales harinas tales panes: granos, harinas y productos de panificación en Iberoamérica. A. E. León y C. M. Rosell (eds.), pp 403-438. Báez, H. ed, Argentina.

Patane, C., Lacoponi, E. y Raccuia, S.A. 2004. Physico-chemical characteristics, water absorption, soaking and cooking properties of some Sicilian populations of chickpea (Cicer arietinum L.). International Journal of Food Science and Nutrition. 55: 547-554.

Pyle, E.J. 1982. Bakin Science and Technology. Pyler, E.J. ed. Siebel Publishing Company, Chicago, III, USA. Vol 1. pp. 106-109.

Ros, B.G., Periago, C.M.J. y Pérez, C.D. 2010. Cap. 6. Legumbres, verduras y productos hortícolas. En: Tratado de Nutrición, Tomo II. Composición y calidad nutritiva de los alimentos. A. Gill Hernández. (ed), pp 157-158. ed. Médica Panamericana, España.

SAS. 2000. Statistical Analyses System. The SAS System for Windows, Release V9.0. SAS Institute Inc. Cary, NC.

Serna, S. (2005). Química, almacenamiento e industrialización de cereales (2a edición). México, D.F.: AGT Ediciones.

Torres, G.M.P., Jiménez, M.M.T. y Bárcenas P.M.E. 2014. Harinas de frutas y/o leguminosas y su combinación con harina de trigo. Temas Selectos de Ingeniería de Alimentos. 8 (1): 94 102.

Yamsaengsung, R., Schoenlechner, R. y Berghofer, M. 2010. The effects of chickpea on the functional properties of White and whole wheat bread. International Journal of Food Science and Technology. 45 (3): 610-620.

Zuleta, A., Binaghi, M.J., Greco, C.B., Aguirre, C., De la Casa, L. y Ronayne F.P.A. 2012. Diseño de panes funcionales a base de harinas no tradicionales. Revista Chilena de Nutrición. 39 (3): 58-64. 